\title{
Effectiveness of synthetic hydroxyapatite versus Persian Gulf coral in an animal model of long bone defect reconstruction
}

\author{
A. Meimandi Parizi • A. Oryan $\cdot$ Z. Shafiei-Sarvestani • \\ A. Bigham-Sadegh
}

Received: 9 February 2013/ Accepted: 22 July 2013/Published online: 29 August 2013

(c) The Author(s) 2013. This article is published with open access at Springerlink.com

\begin{abstract}
Background There is a continuing search for bone substitutes to avoid or minimize the need for autogenous bone grafts. Hydroxyapatite, a crystalline phase of calcium phosphate found naturally in bone minerals, has shown tremendous promise as a graft material. Coral is an osteoconductive material used as a bone graft extender. This study examined the effect of hydroxyapatite and Persian Gulf coral on osteogenesis in vivo using a rabbit model of bone healing.

Materials and methods A critical-size defect of $10 \mathrm{~mm}$ elongation was created in the radial diaphysis of 36 rabbits and supplied with either hydroxyapatite or coral or left empty (control group). Radiographs of each forelimb were taken postoperatively on day 1 and then at 2, 4, 6, and 8 weeks postinjury to evaluate bone formation, union, and remodeling of the defect. The operated radiuses were removed on the 56th postoperative day and were grossly and histopathologically evaluated. In addition, biomechanical testing was conducted on the operated and normal forelimbs of half of the animals of each group.

Results In radiological evaluation, bone formation and union were significantly superior in the coral and
\end{abstract}

A. M. Parizi - Z. Shafiei-Sarvestani

Department of Veterinary Surgery and Radiology, School of Veterinary Medicine, Shiraz University, Shiraz, Iran

A. Oryan

Department of Veterinary Pathobiology, School of Veterinary Medicine, Shiraz University, Shiraz, Iran

A. Bigham-Sadegh ( $₫)$

Department of Veterinary Surgery and Radiology, School of Veterinary Medicine, Shahrekord University, Shahrekord, Iran e-mail: dr.bigham@gmail.com hydroxyapatite groups in comparison with the control group on the 42nd and 56th day postinjury $(P<0.05)$. There were no statistical differences between groups in remodeling criteria at the 56th day postinjury $(P>0.05)$. In histopathological evaluation, the union scores of the rabbits administered hydroxyapatite or coral were statistically superior to those of the animals of the control group on the 56th day postinjury $(P<0.05)$. In biomechanical evaluation, the control group showed weakness of biomechanical properties in comparison with the coral and hydroxyapatite groups $(P<0.05)$.

Conclusions According to this study, significant difference was not observed between hydroxyapatite and natural coral and these two materials were significantly better than the control group at 8 weeks postinjury.

Keywords Persian Gulf coral · Hydroxyapatite . Radius · Bone healing $\cdot$ Rabbit

\section{Introduction}

There is a continuing search for bone substitutes to avoid or minimize the need for autogenous bone grafts. Autografts are most widely used by surgeons. These grafts contain viable cells such as bone marrow osteoprogenitor cells, collagenous matrix, and noncollagenous extracellular growth and differentiating factors. Consequently, autograft is the preeminent therapy for bone repair, because it is capable of osteogenesis, osteoinduction, and osteoconduction. However, a number of disadvantages such as morbidity at the donor site, the need for general anesthesia or sedation, as well as the occasional need for more than one surgical field have previously been described in application of autografts. In addition, graft survival is unpredictable, its 
resorption cannot be foretold, and its availability is limited $[1,2]$. It is for these reasons that, in recent years, several biocompatible materials have emerged as substitutes for autologous bone. Biocompatible materials can be classified into two major groups: organic and synthetic. Biological biomaterials can be allogeneic or homologous (human cortical bone and demineralized bone matrix or demineralized freeze-dried bone), heterologous, or xenogeneic (organic bovine, porcine, caprine, or coral-derived hydroxyapatite) and replicating (morphogenetic proteins). Among the synthetic biomaterials, application of artificial or synthetic hydroxyapatite, i.e., bioglass and bioceramics, is more common in orthopedic surgery [3].

Recently, bone morphogenetic proteins (BMPs) have been used in clinical trials to enhance bone healing properties [4-6]. It has been stated that BMPs are able to stimulate local undifferentiated mesenchymal cells to transform into osteoblasts (osteoinduction), and lead to early bone formation [7-10]. More study is still necessary to identify which BMPs have greater osteoinductive action and are more efficient in clinical application. Based on recent literature, it seems that bone tissue engineering is the newest option for promoting and accelerating the healing potential of bone defects [11]. In bone tissue engineering, it is possible to combine synthetic scaffolds with biological biomaterials to stimulate cell infiltration and new bone formation, and to enhance the healing process. In this regard, gene therapy (transfer of genes that code growth factors such as BMPs to target cells with the help of a plasmid or viral vector) may provide promising results. However, concern regarding transinfection of the target cell with the gene remains an unresolved issue [12-15].

Stem cells such as adipose-derived stem cells (ASCs) could differentiate into the osteogenic lineage. Furthermore, osteoid matrix formation has been observed when osteoinduced human ASCs were seeded onto hydroxyapatite/tricalcium phosphate scaffolds and implanted subcutaneously in nude mice [16]. Cowan et al. [17] demonstrated that osteoinduced ASCs along with apatitecoated polylactic-coglycolic acid scaffold could repair a critical-sized calvarial defect in a mouse model. Meanwhile, Dudas et al. [18] showed that ASCs in combination with gelatin gel could repair a non-critical-sized defect in a rabbit model with follow-up of 6 weeks. All these results indicate that ASCs could be an alternative cell source for bone engineering [19].

Hydroxyapatite, a crystalline phase of calcium phosphate found naturally in bone minerals, has shown tremendous promise as a graft material. It exhibits initial mechanical rigidity and structure, and demonstrates osteoconductive as well as angiogenic properties in vivo [20]. Additionally, fabricated porous hydroxyapatite scaffolds have been reported to promote strong mechanical interlocking with host bone tissue [20, 21]. Since the extent of bony ingrowth within the scaffold, the functionality of newly regenerative bone tissue, and the development of a vascularized network within the scaffold are dictated by the porous scaffold architecture, extensive studies have been performed to optimize new biomaterials needed for maximal bone tissue integration [22].

Certain coral species form a structure that resembles matrix or bone. Each species builds a structurally and geometrically typical calcium carbonate skeleton. Choice of an appropriate species therefore enables a desired and constant implant structure to be achieved. More than 2,000 coral species have been described from the intertropical area, and, of these, 14 have been studied as possible bone substitutes. The following genera have already been used as bone grafts: Pocillopora, Acropora, Montipora, Porites, Goniopora, Fungia, Polyphyllia, Favites, Acanthastrea, Lobophyllia, and Turbinaria [23]. The most prominent species were Porites lutea and P. compressa from the Persian Gulf and Kish Island. The porosity of the skeleton is around $50 \%$, and the mean size of the pores is $150 \mu \mathrm{m}$, with the pores interconnecting with each other [24]. Calcium carbonate $\left(\mathrm{CaCO}_{3}\right)$ resembles hydroxyapatite in many respects. This material is biocompatible and osteoconductive but, like hydroxyapatite, has no osteoinductive properties [25]. The main difference between $\mathrm{CaCO}_{3}$ and hydroxyapatite is the resorption rate. Resorption seems to be clinically unimportant with hydroxyapatite, but animal experiments have shown resorption times of only a few weeks when calcium carbonate is used [26]. Therefore, the aim of the present study is to evaluate the effects of Persian Gulf coral and hydroxyapatite on long bone healing processes. The experiment was designed to compare the healing potential of Persian Gulf coral with that of hydroxyapatite, or a defect left empty.

\section{Materials and methods}

Animals and operative procedures

Thirty-six New Zealand white rabbits (12 months old, mixed sex, weight $2.0 \pm 0.5 \mathrm{~kg}$ ) were kept in separate cages, fed a standard diet, and allowed to move freely during the study. The animals were randomly divided into three equal groups as coral group $(n=12)$, hydroxyapatite group ( $n=12$ ), and empty group ( $n=12$, control group). All animals were anesthetized by intramuscular administration of $40 \mathrm{mg} / \mathrm{kg}$ ketamine hydrochloride and $5 \mathrm{mg} / \mathrm{kg}$ xylazine. The right forelimb in all animals was prepared aseptically for operation. A 5-cm skin incision was made craniomedially over the forelimb, and the radius was exposed by dissecting the surrounding muscles. A $10-\mathrm{mm}$ 
segmental defect was then created in the middle portion of each radius as a critical-size bone defect. The defect of the animals in the coral group was filled with Persian Gulf coral segments. In the hydroxyapatite group, the bone defect was filled with hydroxyapatite segments (OS Satura $^{\circledR}$; Isotis Co., The Netherlands), while the defects of the animals of the control group were left empty. The animals were housed in compliance with our institution's guiding principles for the care and use of animals. The local Ethics Committee for animal experiments approved the design of the experiment.

\section{Preparation of coral implants}

Coral exoskeleton from Porites sp. (Kish Island, Persian Gulf, Iran) was used in the form of cylindrical blocks $2 \mathrm{~mm}$ in diameter and $3 \mathrm{~mm}$ long. The coral implants were sterilized by autoclaving, which did not affect the composition [27]. The implants were shaped into a cylindrical segmented shape to allow them to fill the created defects.

\section{Postoperative evaluations}

\section{Radiological evaluation}

To evaluate bone formation, union, and remodeling of the defect, radiographs of each forelimb were taken postoperatively on day 1 and then at 2, 4, 6, and 8 weeks postinjury. The results were scored using the modified Lane and Sandhu scoring system [28] (Table 1).

\section{Gross evaluation}

The operated radial bones were removed on the 56th postoperative day; at this time, the operated radius was evaluated for gross signs of healing. Examination and blinded scoring of the specimens included presence of bridging bone indicating complete union $(+3$ score), presence of cartilage, soft tissue or cracks within the defect indicating possible unstable union $(+1$ or +2 score), or complete instability at the defect site indicating no union $(0$ score).

\section{Histopathological evaluation}

Eight weeks after operation, the rabbits were euthanized for histopathological and biomechanical evaluation. The histopathological evaluation was carried out on six rabbits chosen randomly from each group. The right forelimb of each animal was harvested and dissected free of soft
Table 1 Modified Lane and Sandhu radiological scoring system

\begin{tabular}{lr}
\hline Bone formation & 0 \\
No evidence of bone formation & 1 \\
Bone formation occupying $25 \%$ of the defect & 2 \\
Bone formation occupying $50 \%$ of the defect & 3 \\
Bone formation occupying $75 \%$ of the defect & 4 \\
Bone formation occupying $100 \%$ of the defect & \\
Union (proximal and distal evaluated separately) & 0 \\
No union & 1 \\
Possible union & 2 \\
Radiographic union & 0 \\
Remodeling & 1 \\
No evidence of remodeling & 2 \\
Remodeling of medullary canal & \\
Full remodeling of cortex & 4 \\
Total points possible per category & 2 \\
Bone formation & 2 \\
Proximal union & 2 \\
Distal union & 10 \\
Remodeling & \\
Maximum score & \\
\hline
\end{tabular}

tissues. Sagittal sections containing the defect were cut with a slow-speed saw. Each slice was then fixed in $10 \%$ neutral buffered formalin. The formalin-fixed bone samples were decalcified in $15 \%$ buffered formic acid solution and processed for routine histological examination. Two 5- $\mu \mathrm{m}$ thick sections were cut from the centers of each specimen and stained with hematoxylin and eosin. The sections were blindly evaluated and scored by two pathologists according to the Emery scoring system [29], and based on this scoring system the defects were evaluated as follows: gap empty (score 0), filled with fibrous connective tissue only (score 1 ), more fibrous tissue than fibrocartilage (score 2), more fibrocartilage than fibrous tissue (score 3), fibrocartilage only (score 4), more fibrocartilage than bone (score 5), more bone than fibrocartilage (score 6), and filled only with bone (score 7).

\section{Biomechanical evaluation}

Biomechanical testing was conducted on the injured and normal contralateral bones of half of the rabbits of each group. The tests were performed using a universal tensile testing machine (Instron, London, UK) [30-32]. The threepoint bending test was performed to determine the mechanical properties of the bones. The bones were placed horizontally on two rounded supporting bars located at a separation of $30 \mathrm{~mm}$, and were loaded at the midpoint of the diaphysis by lowering a third bar so that the defect was in the middle and at equal distance from each grip. The 
Table 2 Radiographical findings for bone formation at various postoperative intervals

\begin{tabular}{lllll}
\hline Postoperative days & \multicolumn{2}{l}{ Median $($ min-max $)$} & $P^{\mathrm{a}}$ \\
\cline { 2 - 5 } & Control $(n=12)$ & Coral $(n=12)$ & Hydroxyapatite $(n=12)$ \\
\hline 14 & $0(0-1)$ & $0(0-0)$ & $0(0-0)$ & 0.1 \\
28 & $1(0-1)$ & $1(1-2)$ & $1(0-2)$ & 0.06 \\
42 & $1(0-3)$ & $2(1-3)^{\mathrm{b}}$ & $3(1-3)^{\mathrm{c}}$ & $\mathbf{0 . 0 4}$ \\
56 & $2(1-3)$ & $3(2-3)^{\mathrm{d}}$ & $3(2-4)^{\mathrm{e}}$ & $\mathbf{0 . 0 5}$ \\
\hline
\end{tabular}

Significant $P$ values are presented in bold

a Kruskal-Wallis nonparametric ANOVA

b $P=0.03$ (compared with control by Mann-Whitney $U$ test)

c $P=0.04$ (compared with control by Mann-Whitney $U$ test)

${ }^{\mathrm{d}} P=0.02$ (compared with control by Mann-Whitney $U$ test)

e $P=0.01$ (compared with control by Mann-Whitney $U$ test)

bones were loaded at a rate of $10 \mathrm{~mm} / \mathrm{min}$ until fracture occurred. The behavior of each specimen under loading was characterized by determining the following parameters from the load deformation to destruction curve:

1. Tan $\alpha$ : the coefficient of inclination for the linear portion of the load-deformation curve represents the index of stiffness of the material, expressed in $\mathrm{N} / \mathrm{mm}$. It is easily calculated by measuring the slope of a line drawn tangent to the curve at any defined point. The slope gives the approximate stiffness of the preparation.

2. Ultimate strength: the highest registered load $(\mathrm{N})$.

3. The specimen's extension at the ultimate strength region. The term "strain" means the fractional increase in length of the material due to an applied load. It is calculated by dividing the extension by the original length of the specimen. Strain is more useful than extension, because it minimizes the influence of length measurement error and does not depend on the specimen size.

4. Stress: the ultimate strength divided by the crosssectional area.

The data derived from the load-deformation and stressstrain curves were expressed as mean \pm standard error on the mean (SEM) for each group, and the maximum load, stiffness, stress, and strain were measured and recorded.

\section{Statistical analysis}

The radiological, clinical, and histopathological data were compared by Kruskal-Wallis, nonparametric analysis of variance (ANOVA). When $P$ values were found to be $<0.05$, pairwise group comparisons were performed by Mann-Whitney $U$ test. The biomechanical data were compared by Student's $t$ test between the treated and normal limb data, and one-way ANOVA test was used for biomechanical analysis between the treated bones of all groups (SPSS version 17 for Windows; SPSS Inc., Chicago, USA).

\section{Results and discussion}

Radiological findings

There was significant difference in bone formation between the defects in the animals of the control group versus those of the coral and hydroxyapatite groups on the 42nd and 56 th day postinjury $(P<0.05)$. By day 42 and 56, there was $50-75 \%$ bone formation in the defects of the animals of the coral group, 75-100\% bone formation in the animals of the hydroxyapatite group, and $25-50 \%$ bone formation in those of the control group (Table 2; Figs. 1, 2, $3)$.

Bone union had occurred in the rabbits of the hydroxyapatite and coral groups by day 42 and 56 postsurgery, but not in the animals of the control group. In addition, bone union in the animals of the hydroxyapatite and coral groups by day 42 and 56 postsurgery was more prominent than in the control group. This trend continued, with less union occurring in the animals of the control group (Tables 3, 4; Figs. 1, 2, 3).

There were no statistical differences between groups. The animals of the hydroxyapatite group showed better remodeling criteria on day 56 than those of the control group, although statistical analysis did not show any significant differences (Table 5; Figs. 1, 2, 3).

Gross and histopathological findings

The defect areas of the rabbits of both treated groups showed various amounts of new bone formation; however, the bone defects of the control group left blank or generally 
Table 3 Radiographical findings for proximal union at various postoperative intervals

\begin{tabular}{lllll}
\hline Postoperative days & \multicolumn{2}{l}{ Median $($ min-max $)$} & $P^{\mathrm{a}}$ \\
\cline { 2 - 5 } & Control $(n=12)$ & Coral $(n=12)$ & Hydroxyapatite $(n=12)$ \\
\hline 14 & $0(0-0)$ & $1(0-0)$ & $0(0-0)$ & $1(0-1)$ \\
28 & $1(0-1)$ & $1(0-1)$ & $1(1-2)^{\mathrm{c}}$ & 0.5 \\
42 & $1(0-1)$ & $1(1-2)^{\mathrm{b}}$ & $2(1-2)^{\mathrm{e}}$ & $\mathbf{0 . 0 5}$ \\
56 & $1(0-2)$ & $2(1-2)^{\mathrm{d}}$ & $\mathbf{0 . 0 1}$ \\
\hline
\end{tabular}

Significant $P$ values are presented in bold

a Kruskal-Wallis nonparametric ANOVA

b $P=0.02$ (compared with control by Mann-Whitney $U$ test)

${ }^{\mathrm{d}} P=0.05$ (compared with control by Mann-Whitney $U$ test)

c $P=0.02$ (compared with control by Mann-Whitney $U$ test)

e $P=0.01$ (compared with control by Mann-Whitney $U$ test)

Table 4 Radiographical findings for distal union at various postoperative intervals

\begin{tabular}{lllll}
\hline Postoperative days & Median $($ min-max) & & $P^{\mathrm{a}}$ \\
\cline { 2 - 5 } & Control $(n=12)$ & Coral $(n=12)$ & Hydroxyapatite $(n=12)$ \\
\hline 14 & $0(0-1)$ & $0(0-0)$ & $0(0-0)$ & 0.1 \\
28 & $1(0-1)$ & $1(0-1)$ & $1(0-1)$ & 0.5 \\
42 & $2(0-2)$ & $1(0-2)$ & $1(0-2)$ & 0.5 \\
56 & $2(0-2)$ & $2(1-2)$ & $1(1-2)$ & 0.1 \\
\hline
\end{tabular}

Significant $P$ values are presented in bold

${ }^{a}$ Kruskal-Wallis nonparametric ANOVA

contained the least amounts of new bone and were often filled with a mixture of fibrous connective tissue and cartilage. The union scores of the rabbits administered hydroxyapatite or coral were statistically superior to those of the animals of the control group (Table 6). The union scores at macroscopic level correlated closely with the radiographic union scores on day 56 postinjury.

At the histopathologic level, the defects of the animals of the hydroxyapatite and coral groups showed more advanced healing criteria than those of the control group (Table 6). Fibrous nonunion or fibrocartilage in the defects of the animals of the control group was dominant, and the lesions of these animals showed poor revascularization. Bridging callus or histological union did not develop in any of these defects. These criteria led to a very slow healing process in the animals of the control group (Fig. 4).

The defects of two rabbits of the coral group were filled with mature cortical bone, and the lesions in the remaining four rabbits were substituted by fibrocartilage tissues. Although the defects of the animals in the coral group showed some angiogenic activity, the neovascularization was not as good as in the hydroxyapatite group (Fig. 4).

Normal trabecular and woven bone were uniformly formed within the defects of the animals treated with the hydroxyapatite regimen, and the lesions of this group were filled with woven bone and showed proper maturation; however, the defect of one rabbit contained more fibrocartilage than bone. The regenerated bone completely spanned the defect and most histologic union was occurred. Active endochondral ossification and secondary fracture repair took place in the middle of the defects of the animals of the hydroxyapatite and coral groups (Fig. 4). No significant inflammatory response was evident in the lesions of the animals of the different groups at 8 weeks postinjury, although it may have been present earlier.

\section{Biomechanical findings}

There was significant difference between the injured versus normal bone of the control group in terms of ultimate strength $(P=0.01)$ and stiffness $(P=0.04)$, and the normal bones had superior ultimate strength and stiffness compared with their normal contralaterals. However, the ultimate strength in the treated animals of the hydroxyapatite group showed more advanced values that were not statistically significantly different from those of their normal contralaterals (Table 7).

The objective of this study was to evaluate healing of critical-size radial bone defects treated with hydroxyapatite 
Table 5 Radiographical findings for remodeling at various postoperative intervals

\begin{tabular}{|c|c|c|c|c|}
\hline \multirow[t]{2}{*}{ Postoperative days } & \multicolumn{3}{|l|}{ Median (min-max) } & \multirow[t]{2}{*}{$P^{\mathrm{a}}$} \\
\hline & Control $(n=12)$ & Coral $(n=12)$ & Hydroxyapatite $(n=12)$ & \\
\hline 14 & $0(0-0)$ & $0(0-0)$ & $0(0-0)$ & 1.0 \\
\hline 28 & $0(0-0)$ & $0(0-0)$ & $0(0-0)$ & 0.4 \\
\hline 42 & $0(0-0)$ & $0(0-0)$ & $0(0-0)$ & 1.0 \\
\hline 56 & $0(0-1)$ & $1(0-1)$ & $1(0-2)$ & 0.1 \\
\hline
\end{tabular}

Significant $P$ values are presented in bold

${ }^{a}$ Kruskal-Wallis nonparametric ANOVA
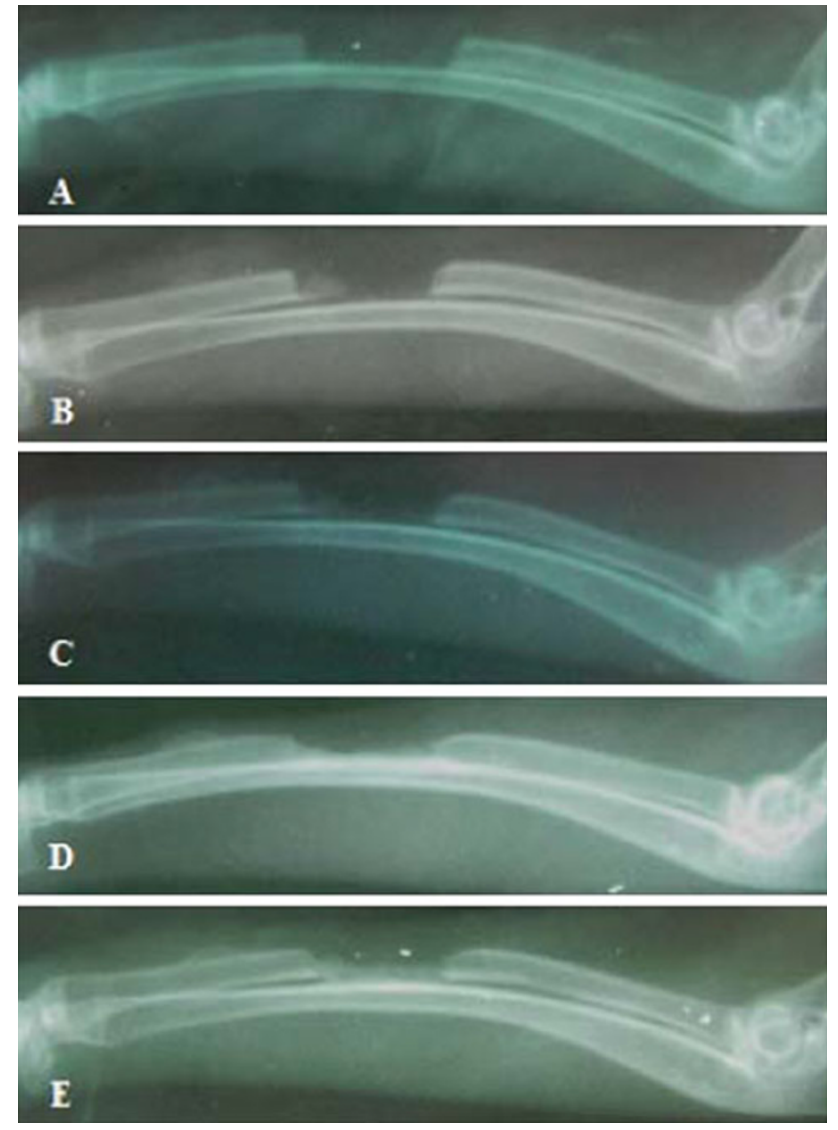

Fig. 1 Radiographs of treated forelimb in control group on postoperative day $1(\mathbf{a}), 14(\mathbf{b}), 28(\mathbf{c}), 42(\mathbf{d})$, and $56(\mathbf{e})$

or natural coral in comparison with a control (empty) group. The radial bone defect of rabbits is a convenient model for study of bone-regenerative materials because of its lack of fixation requirements [33]. Segmental defects as long as $10 \mathrm{~mm}$ were created in the middle portion of the radius to induce nonunion defect and prevent spontaneous and rapid healing [34].

Autogenous bone still remains the "gold standard" of bone graft material in all facets of orthopedic surgery and is commonly used as a standard against which allografts and graft substitutes are compared [35-40]. They may provide
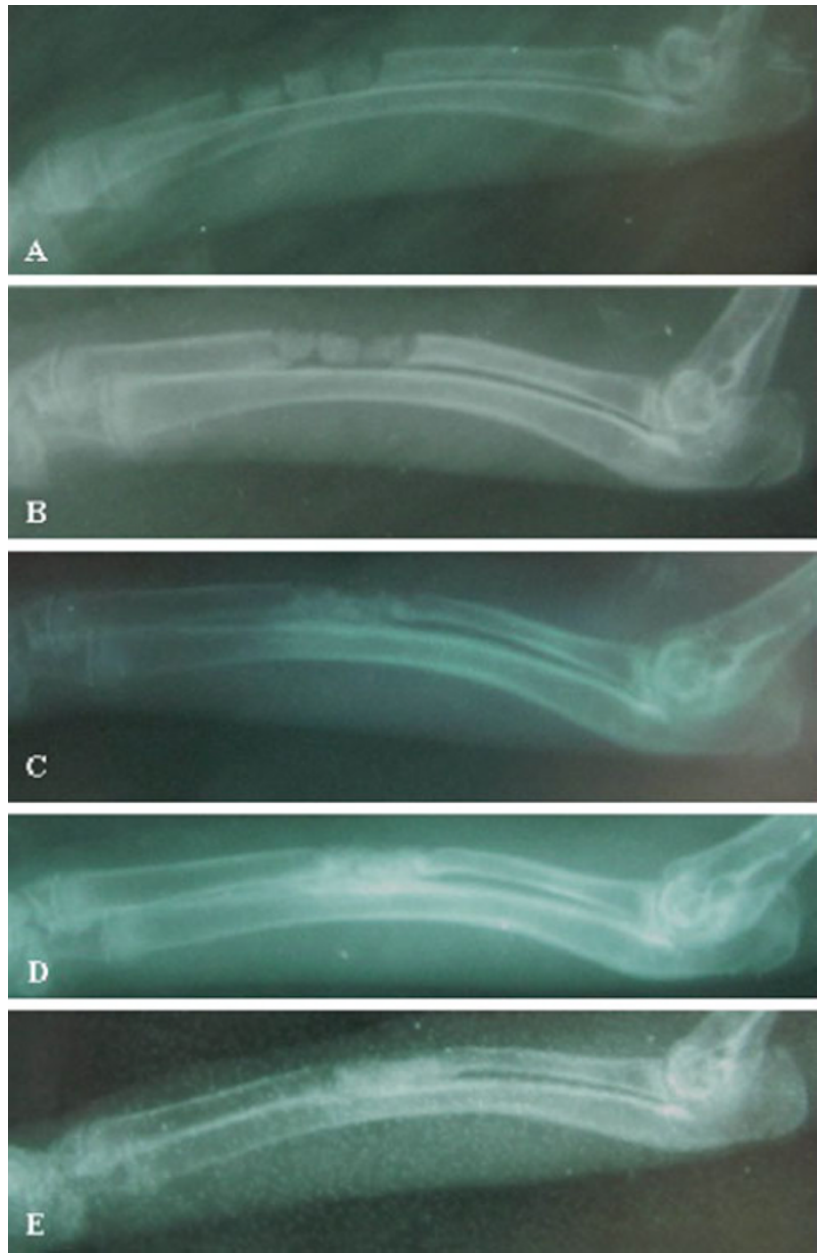

Fig. 2 Radiographs of treated forelimb in hydroxyapatite group on postoperative day 1 (a), 14 (b), 28 (c), 42 (d), and 56 (e)

a source of osteoprogenitor cells (osteogenesis), induce formation of osteoprogenitor cells from surrounding tissues (osteoinduction), and provide mechanical support for vascular and bone ingrowth (osteoconduction) [41]. In our study we used three groups for comparison, but it seems that we should have included another group with autogenous bone grafting as a positive control group. However, hydroxyapatite and coral materials act solely as 

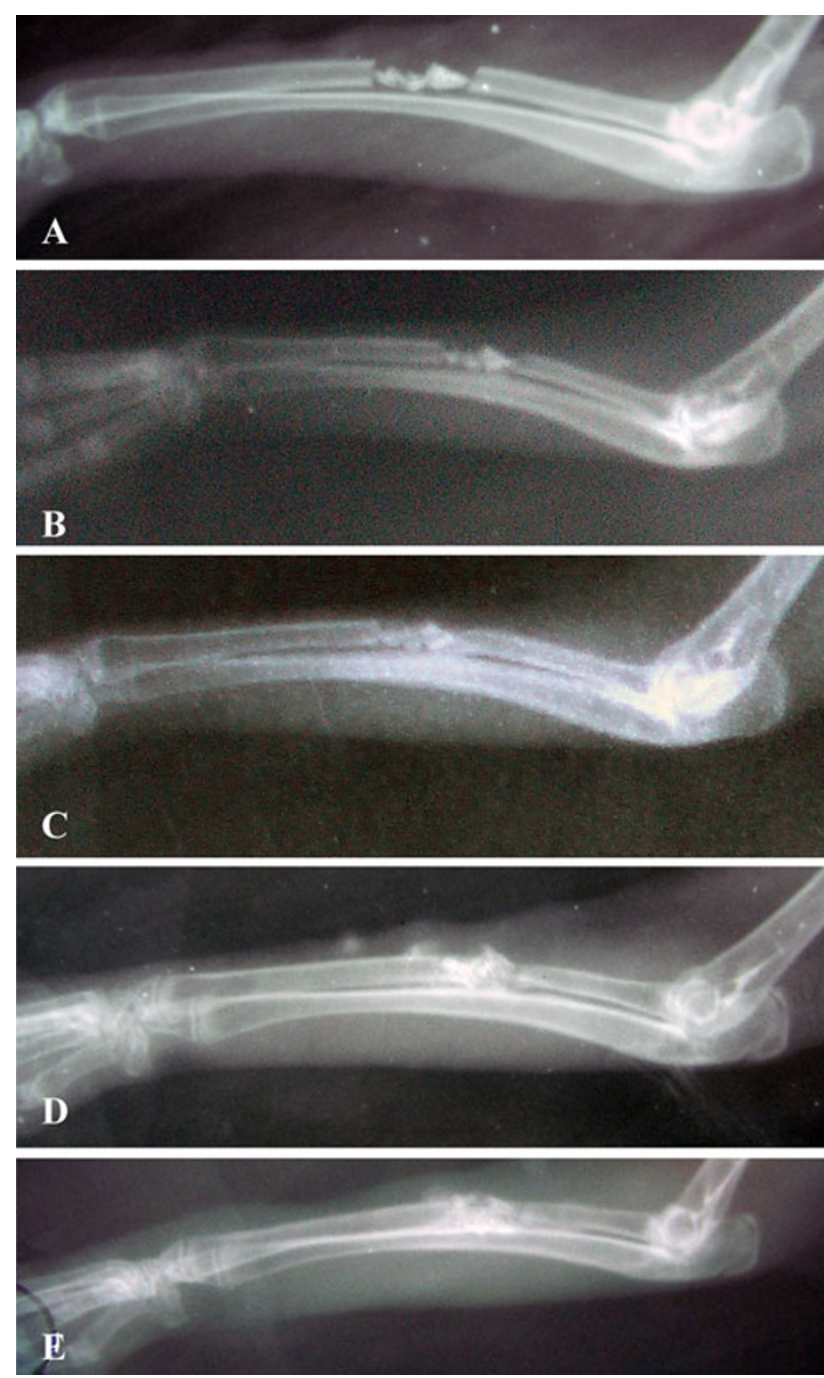

Fig. 3 Radiographs of treated forelimb in coral group on postoperative day 1 (a), 14 (b), 28 (c), 42 (d), and 56 (e) osteoconductive materials and have no osteoinductive properties [20, 25]. These different properties led to the three-group comparison design of our study, and we did not include autograft as an additional group. There are a wide range of biomaterials that could be used as bone substitutes, depending on their bioactivity. Use of calcium phosphate ceramics as implant materials is common, and previous studies [42, 43] indicated that hydroxyapatite (HA) implanted into osseous surgical defects at various sites does not elicit an inflammatory response and is essentially nonresorbable. It has also been shown that HA allows physiologic contouring of a treated site, while it may or may not allow incorporation of bony ingrowth [42, 44, 45]. Clinically, coral has been successfully used in spinal fusion [46, 47], cranial surgery [48], and dentistry [49]. It is osteoconductive but not osteogenic.

Based on the four outcome measures described in this study, it was observed that defects grafted with hydroxyapatite or natural coral showed significantly more bone formation than the negative control (empty defect) at 8 weeks.

Hydroxyapatite, a crystalline phase of calcium phosphate found naturally in bone minerals, has shown tremendous promise as a graft material. It exhibits initial mechanical rigidity and structure, and demonstrates osteoconductive as well as angiogenic properties in vivo [20, $50,51]$. In osteoperiosteal gaps bridged with hydroxyapatite only, the porosities were invaded with fibrous tissue or fibrocartilage tissues and the defects were not filled with bone tissue. Occasionally, bone formation was observed in direct contact with hydroxyapatite, confirming its osteoconductive ability, albeit insufficient to enable union. These findings are similar to those reported using hydroxyapatite. When the gap reaches a critical size, the osteoconductive

Table 6 Bone measurements at macroscopic and microscopic level

\begin{tabular}{|c|c|c|c|c|}
\hline \multirow[t]{2}{*}{ Bone evaluation type } & \multicolumn{3}{|c|}{ Median (min-max) } & \multirow[t]{2}{*}{$P^{\mathrm{a}}$} \\
\hline & Control $(n=6)$ & Coral $(n=6)$ & Hydroxyapatite $(n=6)$ & \\
\hline Macroscopic union ${ }^{*}$ & $1(1-2)$ & $2(1-3)^{\mathrm{b}}$ & $2(2-3)^{\mathrm{c}}$ & 0.00 \\
\hline Microscopic evaluation ${ }^{\dagger}$ & $2(1-5)$ & $6(5-7)^{\mathrm{d}}$ & $6(5-7)^{\mathrm{e}}$ & 0.003 \\
\hline \multicolumn{5}{|c|}{ Significant $P$ values are presented in bold } \\
\hline \multicolumn{5}{|c|}{$\begin{array}{l}\text { Complete union }(+3 \text { score }) \text {, presence of cartilage, soft tissue or cracks within the defect indicating possible unstable union }(+1 \text { or }+2 \text { score }) \text {, } \\
\text { complete instability at the defect site indicating nonunion }(0 \text { score })\end{array}$} \\
\hline \multicolumn{5}{|c|}{$\begin{array}{l}\text { Empty ( } 0 \text { score), fibrous tissue only ( } 1 \text { score), more fibrous tissue than fibrocartilage }(2 \text { score }) \text {, more fibrocartilage than fibrous tissue }(3 \text { score }) \text {, } \\
\text { fibrocartilage only }(4 \text { score }) \text {, more fibrocartilage than bone }(5 \text { score }) \text {, more bone than fibrocartilage }(6 \text { score), bone only ( } 7 \text { score })\end{array}$} \\
\hline \multicolumn{5}{|c|}{${ }^{a}$ Kruskal-Wallis nonparametric ANOVA } \\
\hline \multicolumn{5}{|c|}{ b $P=0.005$ (compared with control by Mann-Whitney $U$ test) } \\
\hline \multicolumn{5}{|c|}{${ }^{\mathrm{c}} P=0.005$ (compared with control by Mann-Whitney $U$ test) } \\
\hline \multicolumn{5}{|c|}{${ }^{\mathrm{d}} P=0.001$ (compared with control by Mann-Whitney $U$ test) } \\
\hline${ }^{\mathrm{e}} P=0.0$ (compared witl & Mann-Whitney $U$ & & & \\
\hline
\end{tabular}


Fig. 4 Photomicrographs from the control group showing fibrous connective tissue in the defect area without bone marrow formation (yellow rectangle), old bone region (white rectangle) $(\mathbf{a}, \mathrm{H} \& \mathrm{E}$ stain $4 \times$ ), and extensive fibrocartilage (b, H \& E stain $40 \times$ ). Photomicrographs from the hydroxyapatite group, showing trabecular bone formation (c, $\mathrm{H} \& \mathrm{E}$ stain $10 \times$ ) and woven bone (d, H \& E stain $40 \times$ ). Photomicrographs from the coral group showing trabecular-pattern bone formation in grafted area (black rectangle) and grafted area with old bone and marrow (white rectangle) $(\mathbf{e}, \mathrm{H} \& \mathrm{E}$ stain $4 \times)$. Note the trabecular bone and chondroplasia zone in the coral group (f, H \& E stain $4 \times$ )
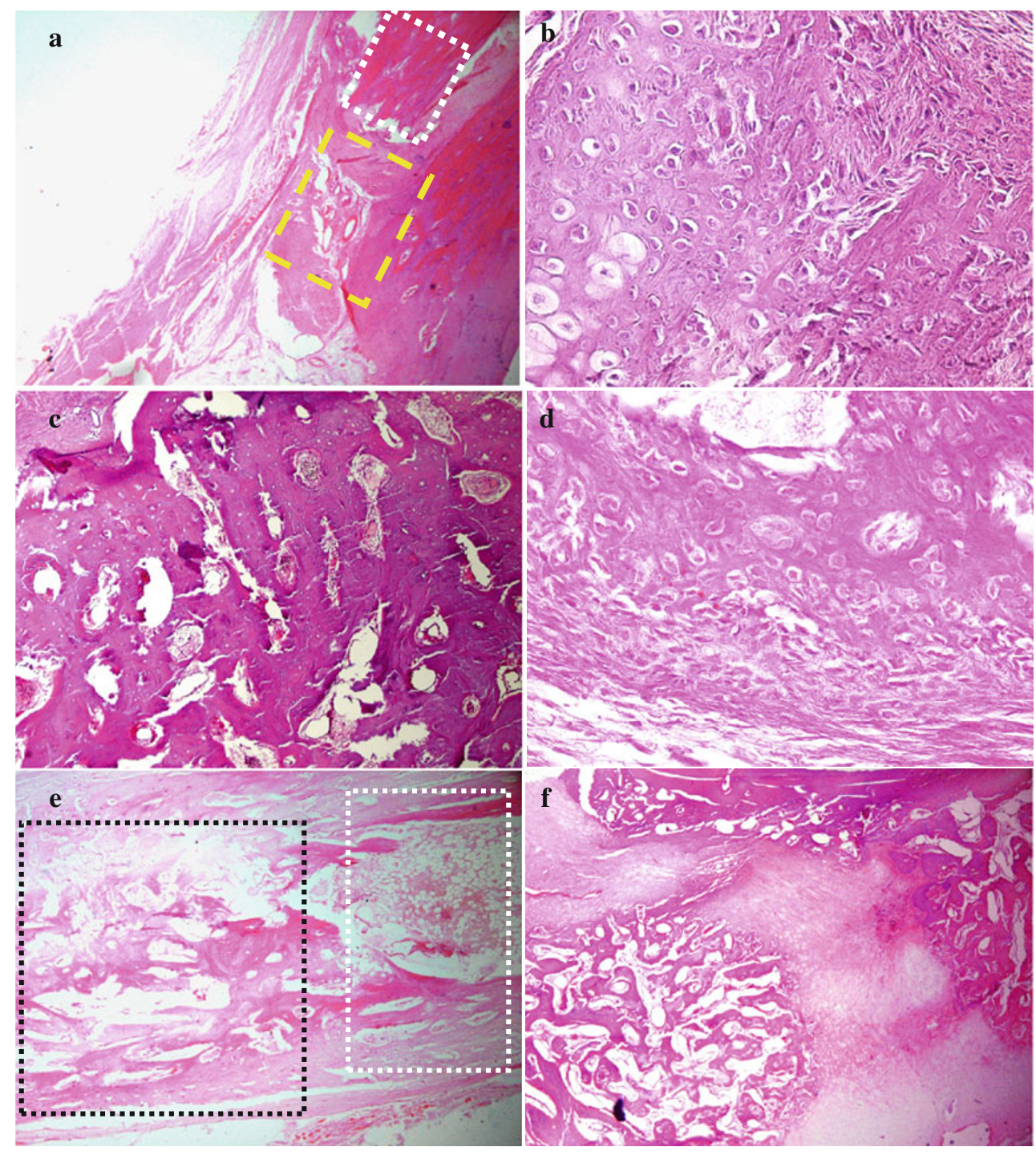

Table 7 Biomechanical findings at 56th postoperative day

\begin{tabular}{|c|c|c|c|c|c|c|}
\hline \multirow[t]{3}{*}{ Three-point bending test criteria } & \multicolumn{6}{|l|}{ Mean \pm SEM } \\
\hline & \multicolumn{2}{|c|}{ Control $(n=6)$} & \multicolumn{2}{|l|}{ Coral $(n=6)$} & \multicolumn{2}{|c|}{ Hydroxyapatite $(n=6)$} \\
\hline & Normal limb & Treated limb & Normal limb & Treated limb & Normal limb & Treated limb \\
\hline Ultimate strength $(\mathrm{N})$ & $66.8 \pm 10.5^{\mathrm{a}}$ & $38.6 \pm 7.5$ & $63.6 \pm 14.5$ & $53.16 \pm 9.5$ & $60.6 \pm 10.5$ & $70.8 \pm 8.4^{\mathrm{b}}$ \\
\hline Stress $\left(\mathrm{N} / \mathrm{mm}^{2}\right)$ & $3.64 \pm 0.7$ & $2.18 \pm 0.3$ & $3.49 \pm 1.1$ & $2.43 \pm 0.43$ & $4.1 \pm 0.83$ & $3.75 \pm 0.71$ \\
\hline Stiffness (N/mm) & $128.3 \pm 7.4^{\mathrm{c}}$ & $91.6 \pm 14.9$ & $133.3 \pm 13.5$ & $88.0 \pm 14.9$ & $96.0 \pm 11.6$ & $75.0 \pm 5.6$ \\
\hline Strain $(\%)$ & $7.9 \pm 0.5$ & $8.4 \pm 0.6$ & $8.35 \pm 0.7$ & $9.3 \pm 0.84$ & $7.1 \pm 1.1$ & $6.7 \pm 0.80$ \\
\hline
\end{tabular}

${ }^{\mathrm{a}} P=0.01$ (normal limb compared with treated limb in control group by Student $t$ test)

b $P=0.05$ (treated limb compared with treated limb in control group by one-way ANOVA test)

c $P=0.04$ (normal limb compared with treated limb in control group by Student $t$ test)

properties of the material are insufficient to fill the gap with formation of new bone [52].

More unexpected was the formation of cortex and medullary canal together with mature lamellar bone observed in most of the cases. Previous in vitro studies showed that artificial bone graft materials support attachment, growth, and differentiation of bone marrow stromal cells [53]. The findings of the present study suggest that 
hydroxyapatite is a suitable material in vivo. It serves as a template to guide bone morphogenesis in a clinically relevant volume.

According to this study, significant difference was not observed between hydroxyapatite and natural coral, and these two materials led to bone formation in a similar way. It has been shown previously that natural coral $\left(\mathrm{CaCO}_{3}\right)$ resembles hydroxyapatite in many aspects. The material is biocompatible and osteoconductive but, similar to hydroxyapatite, has no osteoinductive properties [12]. The main difference between coral and hydroxyapatite is its chemical structure, as hydroxyapatite is calcium phosphate whereas coral is calcium carbonate [25, 26, 54]. In addition, a study by Mora et al. [55] that compared natural coral skeleton versus porous hydroxyapatite for treating periodontal bone defects in human subjects found no significant difference between the use of coral skeleton and porous hydroxyapatite for bony defect filling, and statistical analysis revealed the beneficial effects of using each biomaterial.

The biomechanical evaluation performed in this study indicated initial failure at the interosseous membrane, suggesting a strong load-sharing mechanism through this syndesmosis between the radius and ulna. The syndesmosis was shown to have extensive calcification, accounting for a large fraction of the bone volume in the defect and possibly contributing to the bone ingrowth into the scaffold. This was supported by both histopathologic and radiographic evidence showing new bone growth in a cone-like fashion and from the direction of the interosseous membrane in defects implanted with scaffolds as well as in defects with no treatment. Thus, separating the radius from the ulna for biomechanical testing may damage this tissue. It is also important to consider that the radius and ulna act as a unit in the physiological setting and that it may be more biologically relevant to evaluate them together [56].

Based on the radiological, histopathological, and biomechanical findings of the present study, healing of defects in animals of the control group was not very efficient and the defect area was filled with fibrous tissues and rarely with cartilage instead of osseous tissue. Barnes et al. [57] indicated that chondrocytes derived from mesenchymal progenitors proliferate and synthesize cartilaginous matrix until all fibrinous/granulation tissue is replaced by cartilage. Where cartilage production is deficient, fibroblasts replace the region with generalized fibrous tissue. Discrete cartilaginous regions progressively grow and merge to produce a central fibrocartilaginous plug between the fractured fragments that splints the fracture. Overall, this study demonstrates that both hydroxyapatite and Persian Gulf coral showed significantly more bone formation than the negative control (empty defect) at 8 weeks after surgical operation.

\section{Conflict of interest None.}

Open Access This article is distributed under the terms of the Creative Commons Attribution License which permits any use, distribution, and reproduction in any medium, provided the original author(s) and the source are credited.

\section{References}

1. Bauer TW, Muschler GF (2000) Bone graft materials: an overview of the basic science. Clin Orthop Rel Res 371:10-27

2. Keating JF, McQueen MM (2001) Substitutes for autologous bone graft in orthopaedic trauma. J Bone Joint Surg Am 83$\mathrm{B}: 3-8$

3. Esposito M, Grusovin MG, Coulthard P, Worthington HV (2006) The efficacy of various bone augmentation procedures for dental implants: a Cochrane systematic review of randomized controlled clinical trials. Int J Oral Maxillofac Implants 21:696-710

4. Baltzer AW, Lattermann C, Whalen JD, Wooley P, Weiss K, Grimm M, Ghivizzani SC, Robbins PD, Evans CH (2000) Genetic enhancement of fracture repair: healing of an experimental segmental defect by adenoviral transfer of the BMP-2 gene. Gene Ther 7:734

5. Peng H, Usas A, Olshanski A, Ho AM, Gearhart B, Cooper GM, Huard J (2005) VEGF improves, whereas sFlt1 inhibits, BMP2induced bone formation and bone healing through modulation of angiogenesis. J Bone Miner Res 20:2017-2027

6. Lee JY, Peng H, Usas A, Musgrave D, Cummins J, Pelinkovic D, Jankowski R, Ziran B, Robbins P, Huard J (2002) Enhancement of bone healing based on ex vivo gene therapy using human muscle-derived cells expressing bone morphogenetic protein 2 . Hum Gene Ther 13:1201-1211

7. Bostrom MPG, Lane JM, Berberian WS, Missri AAE, Tomin E, Weiland A, Doty SB, Glaser D, Rosen VM (1995) Immunolocalization and expression of bone morphogenic proteins 2 and 4 in fracture healing. J Orthop Res 13:357-367

8. Cook SD, Baffes GC, Wolfe MW, Sampath TK, Rueger DC (1994) Recombinant human bone morphogenetic protein-7 induces healing in a canine long-bone segmental bone defect model. J Bone Joint Surg Am 76:827-838

9. Kirker-Head AC (1995) Recombinant bone morphogenic protein: novel substances for enhancing bone healing. Vet Surg 24:408-419

10. Reddi AH (1995) Bone morphogenetic proteins, bone marrow stromal cells, and mesenchymal stem cells. Maureen Owen revisited. Clin Orthop Relat Res 313:115-119

11. Bose S, Roy M, Bandyopadhyay A (2012) Recent advances in bone tissue engineering scaffolds. Trends Biotechnol 30(10):546-554

12. Kimelman-Bleich N, Pelled G, Zilberman Y, Kallai I, Mizrahi O, Tawackoli W, Gazit Z, Gazit D (2010) Targeted gene-and-host progenitor cell therapy for nonunion bone fracture repair. Mol Ther 19:53-59

13. Peterson B, Zhang J, Iglesias R, Kabo M, Hedrick M, Benhaim P, Lieberman JR (2005) Healing of critically sized femoral defects, using genetically modified mesenchymal stem cells from human adipose tissue. Tissue Eng 11:120-129

14. Pelled G, Ben-Arav A, Hock C, Reynolds DG, Yazici C, Zilberman Y, Gazit Z, Awad H, Gazit D, Schwarz EM (2009) Direct gene therapy for bone regeneration: gene delivery, animal models, and outcome measures. Tissue Eng Part B Rev 16:13-20

15. Egermann M, Baltzer A, Adamaszek S, Evans C, Robbins P, Schneider E, Lill C (2006) Direct adenoviral transfer of bone 
morphogenetic protein-2 cDNA enhances fracture healing in osteoporotic sheep. Hum Gene Ther 17:507-517

16. Hicok KC, Du Laney TV, Zhou YS, Halvorsen YDC, Hitt DC, Cooper LF, Gimble JM (2004) Human adipose-derived adult stem cells produce osteoid in vivo. Tissue Eng 10:371-380

17. Cowan CM, Shi YY, Aalami OO, Chou YF, Mari C, Thomas R, Quarto N, Contag CH, Wu B, Longaker MT (2004) Adiposederived adult stromal cells heal critical-size mouse calvarial defects. Nat Biotechnol 22:560-567

18. Dudas JR, Marra KG, Cooper GM, Penascino VM, Mooney MP, Jiang S, Rubin JP, Losee JE (2006) The osteogenic potential of adipose-derived stem cells for the repair of rabbit calvarial defects. Ann Plast Surg 56:543

19. Bigham-Sadegh A, Mirshokraei P, Karimi I, Oryan A, Aparviz A, Shafiei-Sarvestani Z (2012) Effects of adipose tissue stem cell concurrent with greater omentum on experimental long-bone healing in dog. Connect Tissue Res 53:334-342

20. Appleford MR, Oh S, Oh N, Ong JL (2009) In vivo study on hydroxyapatite scaffolds with trabecular architecture for bone repair. J Biomed Mater Res A 89:1019-1027

21. Ohgushi H, Dohi Y, Tamai S, Tabata S (1993) Osteogenic differentiation of marrow stromal stem cells in porous hydroxyapatite ceramics. J Biomed Mater Res 27:1401-1407

22. Martin RB, Chapman MW, Sharkey NA, Zissimos SL, Bay B, Shors EC (1993) Bone ingrowth and mechanical properties of coralline hydroxyapatite 1 year after implantation. Biomaterials $14: 341-348$

23. Bouchon C, Lebrun T, Rouvillain JL, Roudier M (1995) The Caribbean Scleractinian corals used for surgical implants. Bull Inst Océanogr 14:111-122

24. Fatemi SMR, Shokri MR (2001) Iranian coral reefs status with particular reference to Kish Island, Persian Gulf international coral reef initiative Indian Ocean regional Workshop, Mozambique: $26-28$

25. Guillemin G, Patat JL, Fournie J, Chetail M (1987) The use of coral as a bone graft substitute. J Biomed Mater Res 21:557-567

26. Guillemin G, Meunier A, Dallant P, Christel P, Pouliquen J (1989) Comparison of coral resorption and bone apposition with two natural corals of different porosities. J Biomed Mater Res 23:765-779

27. Irigaray JL, Oudadesse H, El FH (1993) Effet de la température sur la structure cristalline d'un Biocorail. J Therm Anal 39:3-14

28. Lane JM, Sandhu HS (1987) Current approach to experimental bone grafting. Orthop Clin North Am 18:213-225

29. Emery SE, Brazinski MS, Koka A, Bensusan JS, Stevenson S (1994) The biological and biomechanical effects of irradiation on anterior spinal bone grafts in a canine model. J Bone Jt Surg 76:540

30. Oryan A, Goodship AE, Silver IA (2008) Response of a collagenase-induced tendon injury to treatment with a polysulphated glycosaminoglycan (Adequan). Connect Tissue Res 49:351-360

31. Oryan A, Moshiri A, Meimandi-Parizi AH (2010) Effects of sodium-hyaluronate and glucosamine-chondroitin sulfate on remodeling stage of tenotomized superficial digital flexor tendon in rabbits: a clinical, histopathological, ultrastructural and biomechanical study. Connect Tissue Res 52(4):329-339. doi:10. 3109/03008207.2010.531332

32. Oryan A, Shoushtari AH (2009) Biomechanical properties and dry weight content of the developing superficial digital flexor tendon. Comp Clin Pathol 18:131-137

33. An YH, Friedman RJ (1999) Animal models in orthopedic research. CRC, Boca Raton

34. Bolander ME, Galian G (1983) The use of demineralize bone matrix in the repair of segmental defect. J Bone Jt Surg 68A:1264-1274

35. Alexander JW (1985) Leonard's orthopedic surgery of the dog and cat. WB Saunders, Florida
36. Alexander JW (1987) Bone grafting. Vet Clin North Am Small Anim Pract 17:811-819

37. Brinker WO, Piermattei DL, Flo GL (1997) Bone grafting small animal orthopedics and fracture repair. WB Saunders, Florida, pp $147-153$

38. Fitch R, Kerwin S, Newman-Gage H, Sinibaldi KR (1997) Bone autografts and allografts in dogs. Comp Vet Cont Ed 19:558-575

39. Fox SM (1984) Cancellous bone grafting in the dog: an overview. J Am Anim Hosp Assoc 20:840-848

40. McLaughlin RM, Roush JK (1998) Autogenous cancellous and cortico-cancellous bone grafting. Vet Med 93:1071-1074

41. Albrek T, Johansson C (2001) Osteoinduction, osteoconduction and osteointegration. Eur Spine J 10:S96-S101

42. Wang H, Li Y, Zuo Y, Li J, Ma S, Cheng L (2007) Biocompatibility and osteogenesis of biomimetic nano-hydroxyapatite/ polyamide composite scaffolds for bone tissue engineering. Biomaterials 28:3338-3348

43. White AA, Best SM, Kinloch IA (2007) Hydroxyapatite-carbon nanotube composites for biomedical applications: a review. Int $\mathrm{J}$ Appl Ceram Tech 4:1-13

44. Carter G (1999) Harvesting and implanting allograft bone. AORN 70:659-670

45. Shimazaki K, Mooney V (1985) Comparative study of porous hydroxyapatite and tricalcium phosphate as bone substitute. J Orthop Res 3:301-310

46. Pouliquen JC, Noat M, Verneret C, Guillemin G, Patat J (1989) Coral as a substitute for bone graft in posterior spine fusion in childhood. French J Orthop Surg 3:272-280

47. Zajour W, Dehoux E, Deprey F, Segal P (1992) Use of coral as a bone graft substitute for anterior fusion of lower spine. Orthop Prod News: $38-39$

48. Roux FX, Brasnu D, Loty B, George B, Guillemin G (1988) Madreporic coral: a new bone graft substitute for cranial surgery. J Neurosurg 69:510-513

49. Yukna RA (1994) Clinical evaluation of coralline calcium carbonate as a bone replacement graft material in human periodontal osseous defects. J Periodontol 65:177-185

50. Kilian O, Wenisch S, Karnati S, Baumgart-Vogt E, Hild A, Fuhrmann R (2008) Observations on the microvasculature of bone defects filled with biodegradable nanoparticulate hydroxyapatite. Biomaterials 29:3429-3437

51. Yoshikawa T, Ohgushi H, Nakajima H, Yamada E, Ichijima K, Tamai S (2000) In vivo osteogenic durability of cultured bone in porous ceramics: a novel method for autogenous bone graft substitution. Transplantation 69:128-134

52. Ohgushi H, Goldberg VM, Caplan AI (1989) Repair of bone defects with marrow cells and porous ceramic: experiments in rats. Acta Orthop Scand 60:334-339

53. Petite H, Kacem K, Triffitt JT (1996) Adhesion, growth and differentiation of human bone marrow stromal cells on nonporous calcium carbonate and plastic substrata: effects of dexamethasone and 1,25 dihydroxyvitamin D3. J Mater Sci Mater Med 7:665-671

54. Jarcho M (1981) Calcium phosphate ceramics as hard tissue prosthetics. Clin Orthop Rel Res 157:259

55. Mora F, Ouhayoun JP (1995) Clinical evaluation of natural coral and porous hydroxyapatite implants in periodontal bone lesions: results of a 1 year follow up. J Clin Periodontol 22:877-884

56. Guda T, Walker JA, Pollot BE, Appleford MR, Oh S, Ong JL, Wenke JC (2011) In vivo performance of bilayer hydroxyapatite scaffolds for bone tissue regeneration in the rabbit radius. J Mater Sci Mater Med 22:647-656

57. Barnes GL, Kostenuik PJ, Gerstenfeld LC, Einhorn TA (1999) Growth factor regulation of fracture repair. J Bone Miner Res 14:1805-1815 